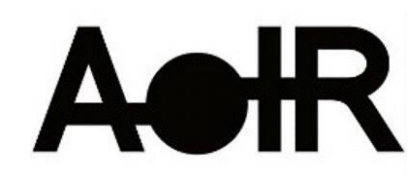

Selected Papers of \#AoIR2020:

The $21^{\text {st }}$ Annual Conference of the

Association of Internet Researchers

Virtual Event / 27-31 October 2020

\title{
TAMING PLATFORM CAPITALISM: STRUGGLES FROM THE GLOBAL SOUTH MEET STRUGGLES FROM THE GLOBAL NORTH
}

\author{
Arturo Arriagada \\ Universidad Adolfo Ibáñez (Chile)/Fairwork Foundation \\ Adam Badger \\ Oxford Internet Institute/Fairwork Foundation \\ Alessio Bertolini \\ Oxford Internet Institute/Fairwork Foundation \\ Macarena Bonhomme \\ Universidad Diego Portales (Chile)/Fairwork Foundation \\ Fabian Ferrari \\ Oxford Internet Institute/Fairwork Foundation \\ Mark Graham \\ Oxford Internet Institute/Fairwork Foundation \\ Ursula Huws \\ University of Hertfordshire \\ Funda Ustek-Spilda \\ Fairwork Foundation \\ Pradyumna Taduri \\ International Institute of Information Technology Bangalore \\ Janaki Srinivasan \\ International Institute of Information Technology Bangalore \\ Suggested Citation (APA): Arriagada, A., Badger, A., Bertolini, A., Bonhomme, M., Ferrari, F., Graham, \\ M., Huws, U., Ustek-Spilda, F., Taduri, P., Srinivasan, J. (2020, October). Taming Platform Capitalism: \\ Struggles From the Global North Meet Struggles From the Global South. Panel presented at AolR 2020: \\ The 21th Annual Conference of the Association of Internet Researchers. Virtual Event: AolR. Retrieved \\ from http://spir.aoir.org.
}


The world over, platforms are reorganising labour markets, reshaping how work is managed, and providing the pre-conditions for new forms of organising and resistance (Woodcock \& Graham 2020; Ravenelle 2019; Rosenblat 2019). At this moment of disruption, platforms are evading labour market regulation designed for a different model of work. This means that, everywhere from Chile to California to Cambodia there are stories of exploitation and struggle. These stories describe the role algorithms play in the organization of labor, offering workers higher levels of flexibility and autonomy. Nevertheless, these technological infrastructures work as mechanisms of control, resulting in low payment, social isolation, and overwork (Wood, et. al 2018). Thus, platform workers can be paid below minimum wages, and have to shoulder all of the risk associated with the work that they do without regulations that resolve those tensions.

This panel brings together scholars whose work seeks to tame platform capitalism understanding how the lives of platform workers are affected by digital platforms. Research on platform labor has been mostly done in the global north, as well as in relation to global platforms like Uber or Amazon (Rosenblat 2019; Scholz 2016). Thus, the panelists, moreover, explore how the lives of platform workers can be improved within the global platform economy by analyzing workers' subjectivities in relation to platforms and the impact of technologies in job quality. To achieve this, this panel brings together scholars from global north and south countries that will map the complexities and subjectivities of platform workers in order to tame platform capitalism. We present a set of articles that address: (1) regulatory resistance that clarifies and redefines the rules that platforms need to abide by; (2) bottom-up resistance of platform workers who seek to organize, subvert, and build alternatives; (3) the ways that action research can support either of those initiatives to ultimately tame some of the worst excesses of platform capitalism.

In order to bring approaches from the South into conversation with approaches form the North, the panelists aim to challenge popular ideas that platform capitalism is a "onesize-fits-all" phenomenon. We locate such ideas in longstanding dismissals of global south research in relation to platform capitalism (Woodcock \& Graham 2020) arguing, instead, that we need to take seriously the subjectivities of workers in a comparative perspective. It is our hope that this session provides the beginning of a larger programme of work that seeks to foster horizontal collaboration between scholars and activists who seek to tame platform capitalism.

\section{References}

Ravenelle, A. (2019). Hustle \& Gig: Struggling and Surviving in the Sharing Economy. California: University of California Press.

Rosenblat, A. (2019). Uberland: How Algorithms Are Rewriting the Rules of Work. California: University of California Press. 
Scholz, T. (2016). Uberworked and Underpaid: How Workers Are Disrupting the Digital Economy. New York: Polity.

Woodcock, J. \& Graham, M. (2020). The Gig Economy: A Critical Introduction. London: Polity.

\title{
TAMING ALGORITHMS ONE CODE AT A TIME: WORKER RESISTANCE STRATEGIES AGAINST AUTOMATED DECISION MAKING SYSTEMS
}

\author{
Funda Ustek-Spilda \\ Fairwork Foundation \\ Fabian Ferrari \\ Oxford Internet Institute/Fairwork Foundation \\ Mark Graham \\ Oxford Internet Institute/Fairwork Foundation \\ Alessio Bertolini \\ Oxford Internet Institute/Fairwork Foundation \\ Adam Badger \\ Oxford Internet Institute/Fairwork Foundation

\section{Introduction}

Algorithms and autonomous decision-making systems play a central role in how work is organised in platform economies around the globe. From allocation of work to determination of salaries or eligibility for access to health care, algorithms sort, assign, allocate and manage labour. Yet, the understandability and explainability of algorithms is not straight-forward and often not even technically possible (Annany and Crawford 2016; Powell et al. 2019). Consequently, workers are often unclear about the terms and conditions of their work; such as when and how much work they will be assigned and how much they will be bringing home at the end of the month. This uncertainty, however, is often presented as flexibility and employees having wider control on their hours and terms of work; and ultimately achieving greater work-life balance (Graham et al. 2017). As a result, it becomes workers' responsibility to seek work and ensure that they have enough to meet their needs, rather than their employer's. Similarly, it becomes workers' responsibility to find a solution when they are not able to work due to illness, care needs or simply when platforms go out of business. Put simply, rather than employers' or social protection systems', it is workers' choice and obligation to figure out ways of survival in platform economy. When things go wrong, it is then not the market forces or the erosure of the welfare state, but the workers themselves are to blame, for not making the right choices, for not managing resources well or for failing to be entrepreneurs that take the initiative. 
Against this background, we examine the ways in which workers cope with the uncertainty they face in platform economies and especially with the unexplainability and seeming unaccountability of the decisions that govern their labour. We approach this through a critical data studies perspective, and seek to understand how workers respond when the basic tenets of their labour are increasingly quantified, automatised and gamified through opaque user interfaces, personalised incentive structures and automated employment relations.

\section{Theoretical Discussion}

Our focus is on the bottom-up resistance strategies and coping mechanisms of platform workers. Power of the powerless, covert and overt survival strategies and subaltern forms of resistance have been widely studied in the literature (Scott 1985, de Certau 1984, Bain \& Taylor 2000). While we also build on these strands of literature, in this paper, we shift the focus to a conceptual framework that has not yet been applied to understand contested labour relations in contemporary platform capitalism: care ethics. There are important reasons for this shift. On the one hand, the theoretical lens of care ethics provides a powerful way of engaging with the power relations that shape decision-making at a wider level, beyond individual dimensions. It introduces relationality as a core concern and signifies that care exists not only with respect to individuals and things; but also through and within them. This means that platforms, their funders as well as regulators, tax agencies and the workers exist in certain configurations of relations to one another and one resistance strategy might unlock or block a variety of these configurations. Second is that, care ethics is an ethical framework and we explore the ethical positioning of expecting workers to resist, alter and change platform economy - rather than regulations, laws and other national authorities. We seek to understand where 'care' lies in this web of relations: the wellbeing of the workers of platform work, or the well-being of business.

In order to do this, we use Puig de la Bellacasa's (2017) framework for care ethics and analyse workers' possibilities and capabilities of dissent, resistance and survival in platform economy through the lens of three analytical foci: thinking with, dissenting within and speaking for; especially when the focus of companies and their investors remain solely on scaling up or otherwise facing 'game over' in the markets in which they operate in. In "thinking with", we explore workers' practices of interpersonal sensemaking: moments in which they come together and explore and develop collective strategies against the platforms they work for. In "dissenting within" we explore day-today covert and overt activities that defy, object to and subvert decisions platforms take about workers. Lastly, in "speaking for", we explore workers' opportunities to be able to collate, bring together and present collective voices to the platforms. In all these aspects, we study both how workers' organise themselves to change their conditions of work that they find unfair; and how the platforms respond to them.

\section{Methods}

The data for this paper comes from a collaborative, multi-site ethnographic fieldwork in India, South Africa, and Germany as part of the Fairwork Project (Graham \& Woodcock 2018). Our data includes interviews and participant observations with both workers in 
the platform economy and platforms themselves. In addition, it involves quantitative data collected from the platforms and photographic and video evidence collected from workers during strikes; screenshots of their payments and incentive structures and automatised and non-automatised responses they receive from the platforms regarding their work. Interview transcripts and other data are then coded to understand and pay attention to possibilities of worker resistance in platform economy.

\section{Key Findings}

\section{Thinking with}

We find that workers are increasingly aware of the fact that decisions about their work are taken autonomously through the interface of the apps they use to access their work on the platforms, and this is why, they often feel powerless to challenge the decisions that are taken about them, including ID blocks, non-payment even after a task is complete or losing incentive structures after a dispute - even when it gets resolved in their favour. Because these apps are also personalised, with personal features, language functionalities, incentive structures, they find it difficult to relate to the experiences of others on the platforms - even though overall they face similar difficulties regarding finding and accessing work, getting orders, and managing their communication with the platform and the customers. We show that for workers who do not have opportunities to see others at work (e.g. domestic workers), thinking with and developing strategies for resistance against platforms become ever more difficult.

\section{Dissenting within}

From creating fake user profiles to be able to complete pre-set incentive requirements to chasing down surveillance cameras to prove to platforms that they have completed a task, we find that workers develop various innovative strategies to deal with the everyday workings of autonomous decision-making systems and to dissent within. Here, we also show, however, these strategies quickly get figured out by the platforms and workers' way of sharing this information/strategies with other workers in the platforms remain very limited; thereby also limiting wider resistances to be formed.

\section{Speaking for}

In this section, we pay particular attention to what happens when workers form and demonstrate collectives, speaking for the problems they face in their work. We analyse how platforms respond to strikes and other collective voicing of disquiet. We note that platforms often respond by throwing the baby with the bathwater: that workers get punished whether or not they partook in a strike as workers in a particular city and district all get penalised, if a strike happens in an area. We note that the automatisation possibilities of blocking IDs, incentives and payment methods enable this "all or none" approach taken by platforms.

\section{Conclusion}


In conclusion, we argue that workers develop innovative strategies to cope with the increasingly automated decisions platforms make about them, and this is their way of 'taming platform capitalism'. Nevertheless, we also show that workers' abilities to 'game the system' remain very limited, as platforms hold an invincible advantage in data and resources, and when they feel they are losing this advantage, they pack up and move to other markets where they continue to hold it. Workers' ways of taming platform capitalism are by no means equivalent to sustained resistance or even worker power in the traditional sense. In fact, they entail serious risks for workers: a normalization of gamified modes of labour control and potential failures to enact long-term social infrastructures of solidarity. This is why we argue for the need for establishing fairness standards for the platform economy (Graham and Woodcock 2018).

\section{References}

Ananny, Mike, and Kate Crawford. 2018. 'Seeing without Knowing: Limitations of the Transparency Ideal and Its Application to Algorithmic Accountability'. New Media \& Society 20 (3): 973-989.

Bain, P. and Taylor, P., 2000. Entrapped by the 'electronic panopticon'? Worker resistance in the call centre. New technology, work and employment, 15(1), pp. 218.

De Certeau, M., 1984. The practice of everyday life. Berkeley: University of California Press.

Graham, Mark, and Jamie Woodcock. 2018. 'Towards a Fairer Platform Economy: Introducing the Fairwork Foundation'. Alternate Routes: A Journal of Critical Social Research 29: 242-253.

Graham, Mark, Vili Lehdonvirta, Alex Wood, Helena Barnard, Isis Hjorth, and David Peter Simon. 2017. 'The Risks and Rewards of Online Gig Work At the Global Margins'. Oxford: Oxford Internet Institute.

Powell, Alison, Arnav Joshi, Paul-Marie Carfantan, Georgina Bourke, lan Hutchinson, and Annalisa Eichholzer. 2019. 'Understanding and Explaining Automated Decisions'. SSRN Scholarly Paper ID 3309779. Rochester, NY: Social Science Research Network.

Puig de la Bellacasa, María. 2017. Matters of Care: Speculative Ethics in More than Human Worlds. University of Minnesota Press.

Scott, J. C. 1985. Weapons of the weak: Everyday forms of peasant resistance. New Haven: Yale University Press. 


\title{
REINVENTING THE WELFARE STATE: DIGITAL PLATFORMS AND PUBLIC POLICIES
}

\author{
Ursula Huws \\ University of Hertfordshire

\section{Introduction}

Drawing on extensive empirical research in 13 European countries, and framed in a perspective informed by feminist political economy, this presentation argues that in the context of digitalisation and globalisation the 20th century normative model of employment is no longer fit for purpose.

This model is firmly embedded in a broader conception of the welfare state which, in turn is strongly linked to notions of national sovereignty and cannot therefore by redesigned in isolation from the broader systems and institutions which govern economic and social redistribution within any given state. It proposes a reinvention of the welfare state to make it suitable for the 21 st century.

This reinvention revisits the 20th century goals of equality, social cohesion and protection from penury and looks critically at how they could be achieved in the context of globalisation. It does not just propose new forms of income redistribution and new rights for workers but also how public bodies can take advantage of the positive potential of platform technologies to deliver new kinds of services that do not just promote these goals but also those of gender equality and addressing the climate emergency.

\section{Results}

Research carried out between 2016 and 2019 by the University of Hertfordshire, funded by the European Foundation for Progressive Studies (FEPS) and the trade union confederation Uni-Europa (Huws, Spencer, Coates and Holts, 2019) found that work for online platforms was not only widespread across the 13 European countries surveyed but also growing very rapidly. The number of people in the UK who said they did work obtained via an online platform at least once a week doubled from an estimated 2.8 million people to an estimated 5.8 million (from $4.7 \%$ to $9.6 \%$ of the adult population) during this 3-year period.

Platform work represents less than $10 \%$ of all income for the largest group of platform workers in all countries, with only a small minority saying that it constitutes all their income. This minority did nevertheless grow in the UK (the only country for which we have trend data) from $5.2 \%$ in 2016 to $9.4 \%$ in 2019 . Despite this, the typical picture is one where the income from platform work is used to top up earnings from other sources. People were turning to the Internet to make money in other ways too: over the same period the proportion of people renting out rooms via online platforms such as Airbnb went up from $8.2 \%$ to $18.7 \%$ while those selling self-made products via platforms like Etsy rose from $10 \%$ to $20.2 \%$. 
The main driver of this phenomenal growth appears to be poverty. During a period when earnings have been falling in real terms or, at best, stagnating for most working class people, and austerity policies have been biting hard, they have been looking for any source of income they can find to make ends meet. One of the most important mechanisms for doing this before the financial crisis - credit - has been much less available and the online economy has become an increasingly important resource to tap into.

Most platform workers report doing more than one kind of platform work. Those doing driving or delivery work range from $1.4 \%$ (in the Netherlands and Sweden) to $12.3 \%$ (in Czechia) of the adult population but in the UK this proportion increased from $1.5 \%$ to $5.1 \%$ between 2016 and 2019 . In every country the proportion doing this kind of platform work is exceeded by those doing more hidden types of platform work providing household services in other people's homes. This ranges from $2.4 \%$ in Sweden to in $11.8 \%$ Czechia. By far the most common type of platform work is carried out virtually, using online means. Consistent with the fact that such work is normally obtained via global platforms, it is unsurprising that by far the highest use of location-independent online platforms is found to be highest in precisely those countries where average earnings (measured in US \$ equivalents) are lowest in real terms, confirming the importance of poverty as a driver to taking up platform work.

The surveys also found a clear link between the use of online platforms to deliver locationally-dependent services (such as driving, food delivery and household services) and time poverty. Those most likely to be users of such services are more likely than average to be working full-time. Platform workers providing local services are also major users of them. Platforms can thus be seen as part of a market solution to the problem of the household 'time squeeze' forming part of a rapidly-growing and self-reinforcing trend - a vicious cycle whereby the need for extra income leads to working longer hours leaving less time available for housework, driving a greater use of platforms which, in turn increases precarious work still further,

The surveys additionally found a widespread and rapidly growing use of the digital organizational and management practices associated with platform work across other sectors of the economy, extending beyond the scope of direct work for these platforms. In 2016 one UK adult in ten reported using an app or website to be informed of new tasks but by 2019 this had more than doubled to $21.0 \%$ of the adult working-age population. In each case, barely half of these workers were platform workers. The use of apps or websites to record work done rose over the same period from $14.2 \%$ to $24.6 \%$. The majority of people reporting these practices were not platform workers. Nearly a quarter $(24 \%)$ of adults surveyed also reported having their work rated by customers, of whom nearly half $(11.7 \%)$ were not platform workers.

\section{Conclusion}

The general 'platformization' of work evidenced in these findings can be seen as the culmination of a series of converging trends that reached critical mass in the years following the financial crisis (Huws, 2017). Across all sectors of the economy, primary, 
secondary or tertiary, whether previously classified as public or private, formal or informal, manual or white-collar, high or low skilled, this emerging model introduces a range of common features whose combined impact is large enough to justify the proposition that a new paradigm of work is in creation, representing the final dissolution of the normative model that emerged in developed economies in the third quarter of the twentieth century. In this new model, as well as experiencing reduced legal protection and low earnings, workers are increasingly managed via online platforms, monitored indirectly and expected to produce measurable outcomes. In a curious paradox, work is increasingly formalised even while it becomes less predictable and more precarious, with workers having to resubmit themselves repeatedly for employment, funding, promotion or inclusion in a particular team, and required to respond at short notice to unpredictable demands for work. This ramifications of this development are huge, since it creates major mismatches between the realities of the labour market and other aspects of social and economic life including welfare systems, labour and consumer regulation and time regimes.

In short, the emergence of this new model calls for a complete redesign of the welfare state. This presentation argues that such a redesign cannot be achieved by attempting to reverse the developments that have taken place in recent decades or tweak existing institutions, but requires a return to the underlying principles of redistribution and equality that underpinned the $20^{\text {th }}$ century welfare state and the creation of new rights and new services to develop a model that is suitable for the conditions of the globalized, digitally-enabled economy of the $21^{\text {st }}$ century.

The ideas proposed here include a new universal charter of workers' rights and a radical reform of the tax and benefit systems to provide an earnings safety net that is genuinely redistributive. They also include recommendations for the development of innovative new uses of platform technologies that put them under more democratic control, enabling them to be used to deliver digitally-enabled services in both the public and private sectors in a manner that helps to rationalise energy use and reduce waste in line with environmental goals. Here, there is a particular focus on services that can support a positive work-life balance, breaking the vicious cycle in which financial poverty drives time poverty, thus contributing to gender equality and a general improvement in the quality of life.

\section{References}

Huws, U., N.H. Spencer, M. Coates \& K. Holts (2019) The Platformisation of Work in Europe: Results from research in 13 European countries, Brussels: Foundation for European Progressive Studies.

Huws, U. (2017) 'Where Did Online Platforms Come From? The Virtualization of Work Organization and the New Policy Challenges it Raises' in P. Meil and V. Kirov (eds) The Policy Implications of Virtual Work, Palgrave Macmillan: 29-48 


\title{
WEAPONS OF THE WEAK IN A DIGITAL AGE? THE CASE OF FOOD DELIVERY WORKERS IN BANGALORE, INDIA
}

\author{
Pradyumna Taduri \\ International Institute of Information Technology Bangalore \\ Janaki Srinivasan \\ International Institute of Information Technology Bangalore
}

Based on a study of the organization of work on a leading food delivery platform in India, this paper will examine the range of ways in which workers have adapted to their platform-based routines, including by subverting aspects of its working. On-demand food delivery platforms in India have now been in operation for about five years. Despite media reports that have started to highlight the working conditions of platform workers, the legal framework within which platforms operate in India is unclear. Moreover, formal organisation among workers is also relatively rare and varies across different sectors. However, we argue that even without explicit political action, workers have been resisting, subverting and coping with the conditions of platform work, including the technology platform itself, using the "weapons of the weak" (Scott, 1985). In the paper, we highlight everyday acts of resistance as workers make their way through the food delivery process. We argue for a need to recognize the significance of these individual acts of resistance by workers, especially in view of the barriers to formal organization.

\section{Introduction}

Since Ola's inception in 2011 in India, on-demand platforms have grown many fold in the last decade. Outside of ride-hailing services such as Ola, on-demand platform services including food-delivery, couriers, bike taxis, and domestic services, have all found acceptance in urban India. While these platforms offer a source of livelihood in Indian cities (Surie and Koduganti, 2016), critics contend that platforms across the globe do this by circumventing existing labour regulations, and by misclassifying workers as partners or independent contractors (De Stefano, 2016). Despite media and researchers highlighting the poor working conditions of platform workers in recent years, there has been little legislative or state action to address these concerns. Since 2017, organized resistance by workers, including en-masse logouts, has grown (Khanna, 2018; Tiwary, 2019) but continues to face barriers. In this paper, we examine how individual workers have been routinely undertaking strategic acts of resistance even prior to such explicit, and collective acts of resistance.

\section{The Everyday Weapons of Food Delivery Workers}

Based on an ethnography of peasant action in Malaysia in the late 1970s, Scott argues that "subordinate classes throughout most of history have rarely been afforded the luxury of open, organized, political activity" (Scott 1985). Instead, his analysis foregrounds the everyday forms of symbolic resistance carried out by the peasantry. Scott proposes that these acts of "foot dragging, dissimulation, desertion, false compliance" that stop short of outright collective resistance are the preferred weapons 
of relatively powerless groups because they require little planning, draw on implicit understandings and informal networks, represent a form of individual self-help; and avoid any direct, symbolic confrontation with authority.

While based on a peasant culture that is far removed from platform work, we nevertheless find Scott's lens useful for analyzing the actions of platform workers in Bangalore. If we treated only such organized collective action as resistance, we risk assuming that workers buy into the present logics of the platform economy or see no means to resist them. The "Weapons of the Weak" understanding, we find, allows us to appreciate everyday forms of symbolic resistance, including their potential to shape acts of more organized resistance in the future. We use this lens to analyse worker experiences on a leading food delivery platform drawn from a previous study (Taduri 2019). That study was based on participant observation of food delivery work and semistructured interviews with workers of the platform in Bangalore.

We examine how workers interact with digital and human actors to resist and create opportunities at the expense of the platform. The worker application is at the heart of food delivery platform work. It tracks workers' whereabouts and monitors worker activity on the platform. This data is used to generate metrics that determine incentives and power algorithms to manage the assignment of orders. In addition to these digital artifacts, workers also encounter other human actors while resolving order assignments, picking up orders at restaurants, and the actual delivery of orders at customer locations.

\section{Resisting an algorithmic boss}

In the platform we studied, workers' daily schedules are structured by an incentive system. For workers to earn daily and weekly incentives, three key requirements must be met. First, workers must remain logged into the application for a fixed duration. Second, workers must earn a minimum amount. Third, workers may only reject one order a day. These restrictions allow the platform to control workers' availability and where they work. Workers, however, have found a way to game this incentive system along both these parameters.

- Availability: Food delivery work spikes during breakfast, lunch and dinner, with periods of low demand and oversupply of workers in between. In response, some workers choose to confine themselves to locations far away from restaurants. This allows them to engage in other activities while remaining logged in, since it is unlikely for the allocation system to assign orders to workers far away from restaurants. Thus, workers resist the requirement of availability.

- Location: Restaurants on food delivery platforms vary in their popularity and time taken to prepare food. Furthermore, being constantly logged in allows the platform to "throw workers around the city". Workers respond to this by strategically logging out of the application and quickly navigating to the restaurant(s) and location of their choice to be available for orders.

- Creating opportunity through surveillance blind spots: As the intermediary between restaurants, workers and customers, the platform aims to command all 
aspects of the delivery process. Workers have found gaps within the platform's surveillance to create opportunities for themselves. First, workers have formed alliances with restaurant employees who cater to delivery orders. To save time waiting at restaurants to pick up orders, workers rely on such alliances to provide them first priority in a long line of workers waiting for delivery. Second, workers create opportunity by leveraging the platform payment policy that allows payment post-delivery in cash. Workers masquerade as customers and order food that they have no intention of paying for. After they (or a fellow worker) receive the "fake order" for food, and the food is picked up from the restaurant, the 'customer' cancels the order or shuts off their phone, leaving the worker with the food. Workers may then negotiate to divide up the food between themselves and the 'customer'. The transaction catches the platform off-guard, with the platform unable to immediately verify the events and actors involved. While there may be several reasons to "fake" an order, sharing a meal at the expense of the platform is one of the few explicit ways to game an inflexible algorithm for some.

Our goal with these examples was to understand how workers cope with, resist and subvert the food delivery process as envisioned by management and as designed into the technological interface. They fight for the choice of place, time and type of work to perform by subverting the commands of an algorithmic boss. Highlighting these weapons of the weak in the digital era can help us appreciate that the mere absence of outright collective resistance may not always indicate that workers are in step with management control.

\section{References}

De Stefano, V. (2016). The Rise of the 'Just-in-Time Workforce': On-Demand Work, Crowd Work and Labour Protection in the 'Gig-Economy. SSRN Electronic Journal.

Khanna, S. (2018). Striking workers a consequence of failed business models. Livemint.com.

Scott, J. C. (1985). Weapons of the weak: Everyday forms of peasant resistance.Yale University Press.

Surie, A., \& Koduganti, J. (2016). The Emerging Nature of Work in Platform Economy Companies in Bengaluru, India: The Case of Uber and Ola Cab Drivers. E-Journal of International and Comparative Labour Studies, 5(3).

Taduri, P. (2019). Delivering Consent: Work games in on-demand food delivery platforms. Masters Thesis. International Institute of Information Technology Bangalore.

Tiwary, A. (2019). More troubles for India's Zomato as food delivery Drivers go on strike. KrASIA, September 17. 


\section{MIGRANTS AND PLATFORM WORK IN CHILE: MOVING BETWEEN PRECARITY AND INVISIBILITY}

Macarena Bonhomme

Universidad Diego Portales (Chile)

Arturo Arriagada

Universidad Adolfo Ibáñez (Chile)

\section{Introduction}

The gig economy is the digital economic model that has transformed forms of work and labour relations, and has expanded access to the labour market for at least seven million workers globally (Graham \& Woodcock, 2018). This economy, which has had an accelerated growth in recent years, constitutes a broader category of non-standardized and informal jobs that provides income opportunities, but which in turn has been highly criticized for the precarisation, commodification and fragmentation of work (Wood et al., 2018), as well as for the risks involved, as predatory intermediaries, social isolation and discrimination (Graham, Lehdonvirta, et al., 2017). Thus, the confusing nature of definitions of job quality or 'decent work' in policy and theoretical debates (Burchell et al., 2013) becomes even more evident with these new labour configurations. This paper aims to contribute to clarify such a debate through qualitative research methods that address the perceptions of those who most participate in these platforms in Santiago, Chile: migrants from Latin America and the Caribbean. In the context of the recent social explosion and several protests in Chile, resulting from the profound inequality existent, it is urgent to investigate the social implications of this economy that is the digital continuation of the neoliberal capitalist model, reproducing the precarisation of work through increasingly sophisticated and invisible forms.

\section{Migrants, precariousness, and the gig economy}

Under the misleading idea of 'independent' and 'collaborative' work are hidden the precariousness of a system that displaces labour risks and costs towards the figure of the 'worker' (Drahokoupil \& Piasna, 2017), who has no security or guarantees in case of accidents, and that together with the great fluctuation of labour demand and the uncertainty it entails, increases inequality in the labour market (Graham, Hjorth, et al., 2017). However, one of the advantages of gig work is the low entry barriers that allow traditionally excluded sectors to gain access (Drahokoupil \& Piasna, 2017), as is the case with migrants. This is particularly relevant for Latin American and Caribbean migrants in Chile, who have faced in recent years increasingly restrictive immigration policies that have made their immigration status to remain uncertain, which has dramatically impacted their access to the labour market and formal jobs (Bonhomme, 2020). Thus, digital platforms provide a vital way to work and make a living while they settle down in the host country.

Empirical studies reveal abuses and violations of labour rights, such as low wages, long unregulated working hours, and high levels of stress (Graham, Lehdonvirta, et al., 2017) and risk (Graham \& Woodcock, 2018). Above all, higher levels of racial and gender 
exclusion and discrimination faced by workers from both platforms (the product of algorithms) and clients (Adams \& Berg, 2017; Beerepoot \& Lambregts, 2015; Galperin \& Greppi, 2017). According to Galperin and Greppi (2017), information frictions in traditional labour markets are exacerbated on digital platforms, resulting in discrimination based on country of origin: migrant workers are less likely to obtain contracts. In other countries of the Global South, workers have experienced the negative effects of these platforms (Anwar \& Graham, 2019).

\section{Methods}

Our in progress study draws draws upon a collaborative, multi-site ethnographic fieldwork in Santiago, Chile, as part of the Fairwork Project (Graham \& Woodcock 2018). Our data includes in-depth interviews and participant observations with workers in the platform economy $(\mathrm{N}: 18)$. Interview topics included the strategies to relate with the app, the strategies displayed to each other in order to resist the organization of work and discriminatory practices by apps, and the type of information they share amongst their peers. We used a grounded theory approach by combining data collection and analysis (Glasser \& Strauss 1967) in order to refine the concepts and categorical themes presented in the analysis. Interview transcripts and other data are then coded to understand and pay attention to possibilities of worker resistance in platform economy.

\section{Preliminary results}

Thus far, our analysis of data has yielded the following preliminary themes. We examine the strategies gig workers have to resist the constraints and negative impact that these platforms have in their labour conditions as well as in the legal implications working in these platforms have, in the case of apps that are forbidden (i.e. Uber). Preliminary results have shown that social media networks have been key for facing these everyday struggles and continue doing their work. Migrant workers support each other through informal organized groups on What's app or Facebook. They share information to facilitate their activities in order to avoid been inspected by the police and regulators, especially in the case of Uber drivers. We analyse how the platforms that operate outside the law are validated by the workers through these resistance strategies due to the lack of regulations in this sector. Furthermore, how for migrant workers especially, relying on these strategies is mainly due to their migratory condition and the limited working opportunities they have in the traditional labour market.

\section{References}

Adams, A., \& Berg, J. (2017). When Home Affects Pay: An Analysis of the Gender Pay Gap Among Crowdworkers (SSRN Scholarly Paper ID 3048711). Social Science Research Network. https://papers.ssrn.com/abstract=3048711

Anwar, M. A., \& Graham, M. (2019). Does economic upgrading lead to social upgrading in contact centers? Evidence from South Africa. African Geographical Review, 38(3), 209-226. https://doi.org/10.1080/19376812.2019.1589730 
Beerepoot, N., \& Lambregts, B. (2015). Competition in online job marketplaces: Towards a global labour market for outsourcing services? Global Networks, 15(2), 236-255. https://doi.org/10.1111/glob.12051

Bonhomme, M. (2020). Making 'race' at the urban margins: Latin American and Caribbean migration in multicultural Chile [PhD thesis]. Goldsmiths, University of London.

Burchell, B., Sehnbruch, K., Piasna, A., \& Agloni, N. (2013). The quality of employment and decent work: Definitions, methodologies, and ongoing debates. Cambridge Journal of Economics, 38(2), 459-477. https://doi.org/10.1093/cje/bet067

Drahokoupil, J., \& Piasna, A. (2017). Work in the Platform Economy: Beyond Lower Transaction Costs. Intereconomics: Review of European Economic Policy, 52(November-December), 335-340. https://doi.org/10.1007/s10272-017-0700-9

Galperin, H., \& Greppi, C. (2017). Geographical discrimination in digital labor platforms. In M. Graham (Ed.), Digital economies at global margins. MIT Press. https://papers.ssrn.com/sol3/papers.cfm?abstract_id=2922874

Graham, M., Hjorth, I., \& Lehdonvirta, V. (2017). Digital labour and development: Impacts of global digital labour platforms and the gig economy on worker livelihoods. Transfer: European Review of Labour and Research, 23(2), 135-162. https://doi.org/10.1177/1024258916687250

Graham, M., Lehdonvirta, V., Wood, A., Barnard, H., Hjorth, I., \& Simon, D. P. (2017). The Risks and Rewards of Online Gig Work At the Global Margins. Oxford Internet Institute, University of Oxford. https://www.oii.ox.ac.uk/blog/new-reportthe-risks-and-rewards-of-online-gig-work-at-the-global-margins/

Graham, M., \& Woodcock, J. (2018). Towards a Fairer Platform Economy: Introducing the Fairwork Foundation. Alternate Routes: A Journal of Critical Social Research, 29. http://www.alternateroutes.ca/index.php/ar/article/view/22455

Wood, A. J., Lehdonvirta, V., \& Graham, M. (2018). Workers of the Internet unite? Online freelancer organisation among remote gig economy workers in six Asian and African countries. New Technology, Work and Employment, 33(2), 95-112. https://doi.org/10.1111/ntwe.12112 